\title{
A Quest for a New Hot Tearing Criterion
}

\author{
D.G. ESKIN and L. KATGERMAN
}

\begin{abstract}
Hot tearing remains a major problem of casting technology despite decades-long efforts to develop working hot tearing criteria and to implement those into casting process computer simulation. Existing models allow one to calculate the stress-strain and temperature situation in a casting (ingot, billet) and to compare those with the chosen hot tearing criterion. In most successful cases, the simulation shows the relative probability of hot tearing and the sensitivity of this probability to such process parameters as casting speed, casting dimensions, and casting recipe. None of the existing criteria, however, can give the answer on whether the hot crack will appear or not and what will be the extent of hot cracking (position, length, shape). This article outlines the requirements for a modern hot tearing model and a criterion based on this model as well as the future development of hot tearing research in terms of mechanisms of hot crack nucleation and propagation. It is suggested that the new model and criterion should take into account different mechanisms of hot tearing that are operational at different stages of solidification and be based on fracture mechanics, i.e., include the mechanisms of nucleation and propagation of a crack.
\end{abstract}

\section{INTRODUCTION: MECHANISMS OF HOT TEARING}

VARIOUS defects of as-cast product are still frequently encountered in casting practice. One of the main defects is hot tearing or hot cracking, or hot shortness. Irrespective of the name, this phenomenon represents the formation of an irreversible failure (crack) in the still semisolid casting. Although in most works hot tearing is considered as a phenomenon linked to the inadequate compensation by melt flow of solidification shrinkage in the presence of thermal stresses, there are more factors that could be involved in the formation of cracks at supersolidus temperatures.

From many studies ${ }^{[1-8]}$ started already in the 1950 s, and reviewed by Novikov ${ }^{[9]}$ and Sigworth, ${ }^{[10]}$ it appears that hot tears initiate above the solidus temperature and propagate in the interdendritic liquid film. In the course of solidification, the liquid flow through the mushy zone decreases until it becomes insufficient to compensate for the solidification shrinkage at which point the cavities (pores) are formed. Cracks can initiate on these pores. The fracture has a bumpy surface covered with a smooth layer and sometimes with solid bridges that connect or have connected both sides of the crack. ${ }^{[7,8,11-16]}$

Industrial and fundamental studies show that hot tearing occurs in the late stages of solidification when the volume fraction of solid is above 85 to 95 pct and the solid phase is organized in a continuous network of grains. It is also known that a fine grain structure and controlled casting conditions (without large temperature and stress gradients) help to avoid hot cracking.

During direct-chill (DC) casting of aluminum alloys, the primary and secondary cooling causes strong macroscopic

D.G. ESKIN, Senior Scientist, is with the Netherlands Institute for Metals Research, 2628CD, Delft, The Netherlands. Contact e-mail: deskin@nimr.nl L. KATGERMAN, Professor, is with the Department of Materials Science and Engineering, Delft University of Technology, 2628CD, Delft, The Netherlands.

This article is based on a presentation made in the symposium entitled "Solidification Modeling and Microstructure Formation: In Honor of Prof. John Hunt," which occurred March 13-15, 2006, during the TMS Spring Meeting in San Antonio, Texas, under the auspices of the TMS Materials Processing and Manufacturing Division, Solidification Committee. thermal gradients in the billet/ingot, which leads to the uneven thermal contraction in different sections of the billet/ingot. As a result, macroscopic stress causes distortion of the billet/ingot shape (e.g., butt curl, butt swell, rolling face pull-in) or may trigger hot tearing and cold cracking in the weak sections. The terms "hot" or "cold" refer to the temperature range where the cracking occurs-in the semisolid mushy zone or below the solidus, respectively. In DC casting, the name "mushy zone" is frequently applied to the entire transition region between liquidus and solidus, which is misleading, as the semisolid mixture in the top part of the transition region is actually slurry, because the newly formed grains are still freely suspended in the liquid. Only after the temperature has dropped below the coherency temperature is a real mush formed.* On the microscopic

\footnotetext{
*The transition region can be conditionally divided into the slurry and mushy zone. In this article, we adopt that the former is contained between the liquidus and coherency isotherms and the latter, between the coherency isotherm and the solidus. The coherency can be defined as the temperature (or solid fraction) at which the solid grains start to "feel" each other by interacting and tangling. Closer to the solidus, inside the mushy zone, there is another important temperature marking the formation of the continuous network of solid grains that are able to transfer stress; as a result, the mush acquires strength. This temperature is called the "rigidity temperature."
}

level, the solidification shrinkage and thermal contraction impose strains and stresses on the solid network in the mushy zone, which creates the conditions for hot tearing.

The deformation behavior of the mush is very critical for the formation of hot tears. The link between the appearance of hot tears and the mechanical properties in the semisolid state is obvious and has been explored for decades (for example, the reviews in Refs. 9 and 17).

Another important correlation-between the hot cracking susceptibility and the composition of an alloy-has been established on many occasions. A large freezing range of an alloy promotes hot tearing because such an alloy spends a longer time in the vulnerable state in which thin liquid films exist between the dendrites. The liquid film distribution is determined by wetting of grain boundaries, i.e., by surface tension between liquid and solid phases. When the surface tension is low and wetting is good, the liquid tends to spread out over the grain boundary surface, 
which strongly reduces the dendrite coherency, weakens the mush, and may promote hot tearing. Otherwise, the liquid will remain as droplets at the grain junctions so that the solid network holds its strength. It is suggested also that the surface tension of the remaining liquid can produce a Marangoni force that facilitates the removal of precipitating gas from the potential voids and thereby reduces hot tearing. ${ }^{[18]}$ At relatively low fractions of solid, e.g., 80 to 85 pct, the interdendritic liquid can provide a bond between grains that creates a tensile strength of the mush. ${ }^{[19]}$

Much effort has been devoted to the understanding of the hot tearing phenomenon. Compilations of research in this field have been done by Novikov, ${ }^{[9]}$ Sigworth, ${ }^{[10]}$ and Eskin et $a l{ }^{[17]}$ Several mechanisms of hot tearing and conditions that may lead to it are already suggested in literature. Some of those are outlined in Table I and summarized in Figure 1.
One can see that, over the years, much more effort has been put on the conditions required for hot tearing occurrence rather than on the mechanisms of crack initiation and propagation, though the development of porosity that can eventually trigger hot cracking has been studied extensively (e.g., Reference 39); and when it comes to the nucleation and propagation of hot tears, an educated guess frequently replaces experimental proof. Figure 1 also shows that the conditions for and causes of hot tearing can be considered on different length scales, from macroscopic to microscopic, and some of these conditions are important on both mesoscopic and microscopic scales. It is worth to note that most of the existing hot tearing criteria deal with the conditions rather than with the mechanisms of hot tearing.

Over the years, different macroscopic and mesoscopic parameters, such as stress and strain, were considered as

Table I. Summary of Hot Tearing Mechanisms

\begin{tabular}{|c|c|c|}
\hline Mechanisms and Conditions & Suggested and Developed by* & Reference** \\
\hline \multicolumn{3}{|c|}{ Cause of hot tearing } \\
\hline Thermal contraction & Heine (1935), Pellini (1952), Dobatkin (1948) & $20,2,21$ \\
\hline Liquid film distribution & Verö (1936) & 22 \\
\hline Liquid pressure drop & Prokhorov (1962), Niyama (1977) & 40,42 \\
\hline Vacancy supersaturation & Fredriksson et al. (2005) & 23 \\
\hline \multicolumn{3}{|c|}{ Nucleation } \\
\hline Liquid film or pore as stress concentrator & $\begin{array}{l}\text { Patterson et al. (1953, 1967); Niyama (1977); } \\
\text { Rappaz et al. (1999); Braccini et al. (2000); } \\
\text { Suyitno et al. (2002) }\end{array}$ & $47,24,42,41,25,51$ \\
\hline Oxide bi-film entrained in the mush & Campbell (1991) & 8 \\
\hline $\begin{array}{l}\text { Vacancy clusters at a grain boundary or } \\
\text { solid/liquid interface }\end{array}$ & Fredriksson et al. (2005) & 23 \\
\hline
\end{tabular}

Propagation

Through liquid film by sliding

By liquid film rupture

By liquid metal embrittlement

Through liquid film or solid phase depending on the temperature range

Diffusion of vacancies from the solid to the crack
Patterson (1953); Williams and Singer (1960, 1966); Novikov and Novik (1963)

Pellini (1952); Patterson (1953); Saveiko (1961); Dickhaus (1994)

Novikov (1966); Sigworth (1996)

Guven and Hunt (1988)

Fredriksson et al. (2005)
$47,26,27$

$2,47,28,29$

9,10

30

23

\section{Conditions}

Thermal strain cannot be accommodated by liquid flow and mush ductility

Pressure drop over the mush reaches a critical value for cavity nucleation

Strain rate reaches a critical value that cannot be compensated by liquid feeding and much ductility

Thermal stress exceed rupture or local critical stress

Stresses and insufficient feeding in the vulnerable temperature range

Thermal stress exceeds rupture stress of the liquid film
Pellini (1952); Prokhorov (1962); Novikov (1966); Magnin et al. (1996)

Niyama (1977); Guven and Hunt (1988); Rappaz et al. (1999); Farup and Mo (2000)

Pellini (1952); Prokhorov (1962); Rappaz et al. (1999); Braccini et al. (2000)

Lees (1946); Langlais and Griuzleski, (2000); Lahaie and Bauchard (2001); Suyitno et al. (2002)

Bochvar (1942); Lees (1946); Pumphrey and Lyons (1948); Clyne and Davies (1975); Feurer (1977); Kargerman (1982)

Saveiko (1961)
$2,40,9,31$

$42,30,41,44$

$2,40,41,25$

$32,33,34,51$

$35,32,36,37,43,38$

28

*The list of the authors is by no means complete. The references have been chosen to represent the development of ideas.

**References are given in the same order as the authors in the second column. 


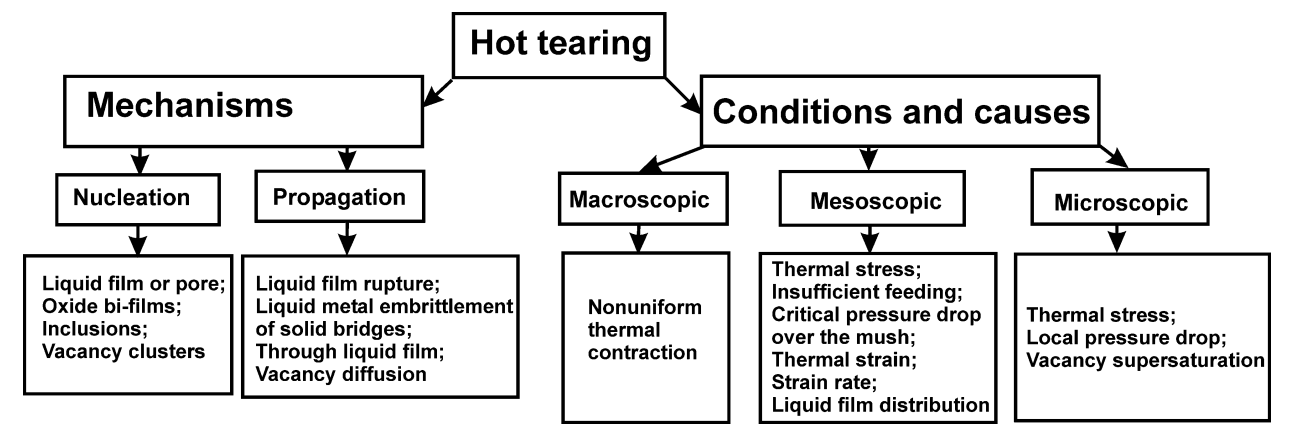

Fig. 1-Summary of mechanisms, conditions, and causes of hot tearing, as suggested to date.

critical for the development of hot tearing. Today, the mesoscopic strain rate is believed to be the most important factor and some modern models are based on it. The physical explanation of this approach is that semisolid material during solidification can accommodate the imposed thermal strain by plastic deformation, diffusion-aided creep, structure rearrangement, and filling of the gaps and pores with the liquid. All these processes require some time, and the lack of time will result in fracture. Therefore, there exists a maximum strain rate that the semisolid material can endure without fracture during solidification. Prokhorov ${ }^{[40]}$ was probably the first to suggest a criterion based on this approach. More recently, an elaborate, strain-rate-based hot tearing criterion was proposed by Rappaz et al. ${ }^{[41]}$

On the mesoscopic and microscopic level, the important factor is believed to be the feeding of the solid phase with the liquid. Within this approach, the hot tear will not occur as long as there is no lack of feeding during solidification. Niyama $^{[42]}$ and Feurer ${ }^{[43]}$ use hindered feeding as a basis for their porosity and hot tearing criteria. The feeding depends on the permeability of the mush, which is largely determined by the structure. Later, a two-phase model of the semisolid dendritic network, ${ }^{[44]}$ which focuses on the pressure depression in the mushy zone, is suggested to describe the hot tear formation. This approach treats the semisolid material as solid and liquid phases with different levels of stress and strain. The pressure drop of the liquid phase in the mush is considered as a cause of a hot tear. An extension of the two-phase model, which includes plasticity of the porous network, is also reported. ${ }^{[45]}$ These models do not distinguish between the pore formation and the crack initiation, the void being considered as the crack nucleus, although the pores should not necessarily develop into a crack. The crack may nucleate or develop from another defect and then propagate through a chain of pores. Logically, bridging and grain coalescence, which determine the transfer of stress and limit the permeability of the mush, are the other important microscopic factors for the development of hot tearing. ${ }^{[46]}$

As we just mentioned, the hot tearing theories that operate with macroscopic mechanical behavior or mesoscopic and microscopic phenomena such as feeding and porosity formation do not take into account the mechanism of crack nucleation and propagation and, in this, are intrinsically weak. The other approach to the description of the hot tearing phenomenon is the application of fracture mechanics that describes initiation and propagation of cracks. The liquid film surrounding the grain at late stages of solidification is considered as a stress concentrator of the semisolid body. ${ }^{[47,48]}$ In this theory, a liquid-filled cavity acts as a crack initiator. The propagation of the crack is determined by the critical stress. ${ }^{[48]}$ The critical stress can be estimated using the Griffith energy balance approach modified by taking into account the plasticity. ${ }^{[49,50]}$ Recently, a formulation of hot tearing as a phenomenon related to microporosity has been proposed. ${ }^{[51]}$ In this approach, the porosity and the hot tearing are considered as sequential events. As a result, there is a possibility to predict simultaneously the occurrence of microporosity and hot tearing. The model uses the feeding difficulties at the last stage of solidification as a starting point of cavity nucleation. The nucleus then grows and becomes at the end of solidification either a micropore or a hot tear, as determined by the Griffith model for brittle crack growth. The fracturemechanical concept of hot tearing can be enriched with the application of a liquid-metal-embrittlement mechanism. ${ }^{[10]}$

It is obvious that the actual hot tearing mechanism includes phenomena occurring on two scales: microscopic (crack nucleation and propagation, stress concentration, structure coherency, wet grain boundaries) and mesomacroscopic (lack of feeding, stress, strain, or strain rate imposed on the structure). Figure 2 illustrates these scales during equiaxed dendritic solidification.

\section{CURRENT HOT TEARING CRITERIA AND THEIR APPLICABILITY TO DC CASTING}

The existing hot tearing criteria, as reviewed elsewhere, ${ }^{[17,52]}$ can be conditionally divided into the two categories: nonmechanical and mechanical. The former type of criteria deals with the vulnerable temperature range, phase diagram, and process parameters, and is represented by the criteria of Clyne and Davies, ${ }^{[6]}$ Feurer, ${ }^{[43]}$ and Katgerman. ${ }^{[38]}$ The latter type of criteria involves critical stress, ${ }^{9,29,33,34,48]}$ critical strain, ${ }^{[9,31,53]}$ or critical strain rate. ${ }^{[25,40-42,54,55]}$

Different casting processes impose specific requirements on the application of hot tearing criteria. That is why some criteria work better for shape casting, whereas others are more suitable for direct-chill casting. There is no doubt that a good hot tearing criterion for DC casting should correctly respond to the casting parameters, e.g., casting speed, ramping rate, and alloy composition, and predict the vulnerable section of a billet or an ingot, e.g., the center of a round billet. Most of the existing criteria have been tested 
for the composition sensitivity by calculating the hot tearing susceptibility of several binary alloys with an attempt to reproduce the so-called lambda curve showing the maximum susceptibility at a certain composition, and most of the existing criteria can do this successfully. However, dynamic parameters such as casting speed and strain rate are usually kept constant upon such testing. Therefore, the compositional sensitivity of a hot tearing criterion does not assure its successful application to a particular casting technology.

The basic phenomena that lead to hot cracking are well established and understood, but a generic criterion that will predict hot cracking under varying process conditions is still not available. Although the earlier simple criteria based on the thermal history of the casting have been extended and improved to include shrinkage and deformation, they are still unable to give reliable predictions under all process conditions. Most of the existing hot tearing criteria do not incorporate the nucleation and propagation of a hot tear, focusing more on the macro-, meso-, and microscopic conditions that may result in rupture (Figure 1).

The ultimate hot cracking criterion needs to combine aspects of thermal history, shrinkage, and porosity formation and constitutive behavior in combination with the evolution of the semisolid microstructure. Current research efforts are aimed, in particular, at the quantitative description of structure evolution and its correlation to cracking. ${ }^{[16,46,56,59-61]}$

Recently, several mechanical and nonmechanical hot tearing criteria were evaluated by implementing them into a thermo-mechanical model of DC casting. ${ }^{[52]}$ The criteria show different results in predicting the hot tearing susceptibility, as shown in Table II.

The criteria of Clyne and Davies and Novikov give results that are inconsistent with casting practice, not showing any sensitivity to the casting speed and position within the billet volume. It is noteworthy to mention that these criteria are very successful in predicting the compositional

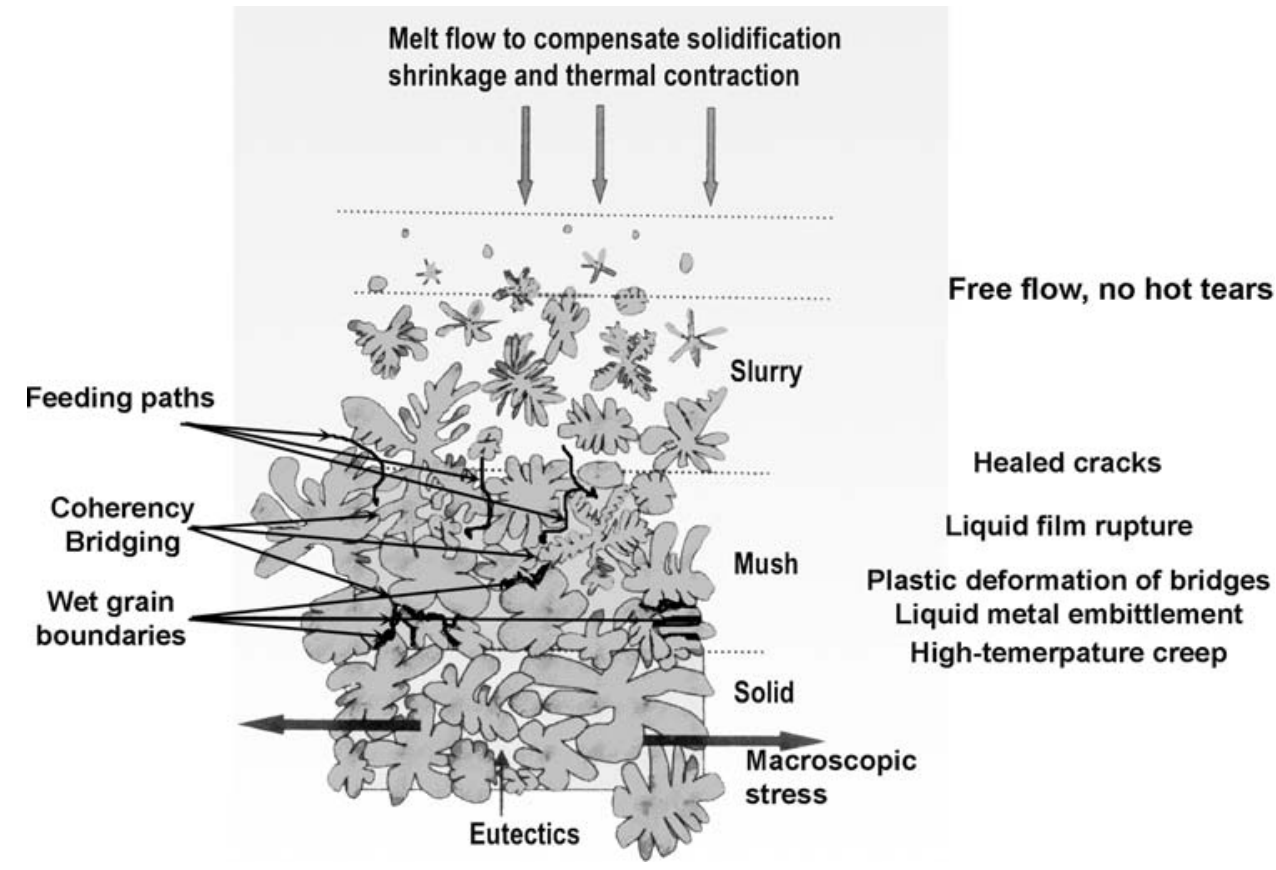

Fig. 2-Different length scales of equiaxed dendritic solidification along with suggested hot tearing mechanisms (the initial sketch is adopted from Ref. 54).

Table II. Sensitivity of Hot Tearing Criteria to the Casting Parameters and Practice upon Direct-Chill Casting ${ }^{[52,57]}$

\begin{tabular}{|c|c|c|c|c|}
\hline Criterion & $\begin{array}{c}\text { Hot Tearing } \\
\text { Increases with } \\
\text { Casting Speed }\end{array}$ & $\begin{array}{c}\text { More Hot } \\
\text { Tears in the } \\
\text { Billet Center }\end{array}$ & $\begin{array}{c}\text { Ramping Casting } \\
\text { Speed during Startup } \\
\text { of the Casting Reduces } \\
\text { Hot Tearing }\end{array}$ & $\begin{array}{c}\text { Correlation with } \\
\text { Actual Cracking } \\
\text { Observed in Practice }\end{array}$ \\
\hline Clyne and Davies ${ }^{[6]}$ & no & no & no & N/A \\
\hline Katgerman $^{[39]}$ & yes & yes & no & N/A \\
\hline Feurer $^{[43]}$ & yes & yes & no & N/A \\
\hline Novikov $^{[9]}$ & no & no & no & N/A \\
\hline Magnin et al. ${ }^{[31]}$ & yes & no & no & no \\
\hline Prokhorov ${ }^{[40]}$ & yes & yes & no & no \\
\hline Rappaz et al. ${ }^{[41]}$ & yes & yes & yes & no \\
\hline Braccini et al. ${ }^{[25]}$ & yes & yes & no & N/A \\
\hline Suyitno ${ }^{[51]}$ & yes & yes & yes & yes \\
\hline
\end{tabular}


dependence of hot tearing and are frequently used for shape casting. The criteria of Feurer, Katgerman, Magnin et al., Prokhorov, Rappaz et al., and Braccini et al. respond correctly to the casting parameters, demonstrating that the increasing casting speed results in an increasing hot tearing susceptibility in the center of the billet, which is in accordance with casting practice. However, most of the tested criteria, except those by Rappaz et al. ${ }^{[41]}$ and Suyitno, ${ }^{[51,57]}$ are not sensitive to the ramping of casting speed during the start-up phase of casting (which is a usual practice to prevent hot cracking). And, when confronted with casting practice, the criteria of Prokhorov, Magnin et al., and Rappaz et al. predict the occurrence of hot cracks, whereas no cracks have been found in billets cast under given conditions. Only the criterion of Suyitno adequately responds to all tested parameters, i.e., casting speed, ramping rate, grain size, position in a billet, and casting practice. The sensitivity of this criterion is, however, a function of correctly chosen values of properties such as Young's modulus of the mush, surface tension between liquid and solid, and permeability of the mush. These parameters are scarcely available and need to be determined experimentally, while the existing experimental techniques are not reliable.

\section{OUTLINE OF HOT TEARING MECHANISMS AS A BASE OF A NEW HOT TEARING CRITERION}

Up to now, hot tearing has been considered as a phenomenon linked to casting and welding processes, and the existing theories, models, and criteria are biased by their applicability to solidification, e.g., by direct link to the solidification shrinkage and limited feeding. Hot tearing is, however, just another example of material failure. Therefore, it should be treated adequately, using the well-developed methodology of fracture mechanics. The challenge nowadays lies not in the adequate description of macroscopic and microscopic stress-strain situations and their correspondence to the parameters and properties of the mushy zone, but rather in finding real factors causing the nucleation and propagation of a hot crack. In fact, some existing theories and models of hot tearing partially describe these factors with the crack initiator presented as a cavity filled with liquid or a pore,${ }^{[41,51]}$ or an oxide bifilm, ${ }^{[8]}$ and with the crack propagation path through the liquid film covering grain boundaries. ${ }^{[10]}$ What is lacking is the completeness of the model. A comprehensive model and a corresponding hot tearing criterion should include nucleation and propagation of hot tears and connect these processes to the microstructure evolution during solidification of the semisolid material; to the macroscopic and microscopic thermo-mechanical situation in the mushy zone; and to the mechanical (or fracture-mechanical) properties of the mushy zone. The last two components are well covered by a large body of publications, though many mechanical properties still need to be determined and the fracture mechanics potential has not been fully exploited. The correspondence between the structure evolution during solidification and the crack nucleation and propagation is studied in much less detail. Let us consider the possible mechanisms of crack nucleation and propagation.
The nucleation of hot cracks is an almost unexplored phenomenon. It is obvious that under any stress-strain conditions, there should be a certain, critical size of a defect (flaw, nucleus) that would enable crack growth. The problem of the crack initiation is today solved by an educated guess, as only recently experimental observations on the crack nucleation upon natural hot tearing have started to emerge: first, for transparent analogues ${ }^{[16]}$ and then for real metals. ${ }^{[58]}$ Usually, the development of a hot crack is studied on samples with a notch, hence, with the artificial crack initiator. ${ }^{[46,64]}$ Based on these observations and "postmortem" examination of hot tear surfaces, the following crack nuclei have been suggested: (1) liquid film or liquid pool; (2) pore or series of pores; (3) grain boundary located in the place of stress concentration; and (4) inclusions that can be easily separated from the surrounding liquid or solid phase, e.g., intermetallic particle or oxide film. It should be noted that pores that are frequently cited as potential hot tear nuclei can originate from gas precipitation, ${ }^{[8]}$ solidification shrinkage, ${ }^{[8]}$ or vacancy supersaturation. ${ }^{[23]}$ Figure 3 summarizes some of the possible crack initiators.

The mechanism of hot tear formation and propagation can be elucidated from observations of fractures. Unfortunately, the reports on hot crack fractures in metallic materials are rare. Most such reports describe the cracking of semisolid alloys at relatively large fractions of liquid, when grain boundaries are completely covered with liquid. In this case, the mechanism of crack propagation-through liquid film by grain separation-is obvious. An example of such alloys is the classic Al-4 pct $\mathrm{Cu}$ alloy. However, alloys with high fractions of liquid in the vulnerable solidification range are in practice not susceptible to hot tearing. ${ }^{[17,59]}$ Cavities and gaps between grains that may form in the mushy zone of such alloys due to solidification shrinkage, presence of notwetted inclusions, thermal contraction, or external tension are easily filled with liquid due to the adequate permeability of the mushy zone and sufficient amount of available liquid that is represented in the final structure by nonequilibrium eutectics. ${ }^{[59]}$ Much more important is the mechanism of crack formation and propagation in alloys containing little solute that are most susceptible to hot tearing. However, the information on semisolid fracture in such alloys is only starting to emerge. If one wanted to summarize the findings available to date, it would appear that bridging of grain boundaries is an essential feature of the fracture surface. Moreover, the closer the semisolid material gets to the temperature range of its maximum vulnerability to hot cracking, i.e., 90 to 95 pct solid, the greater the fraction of grain boundaries connected to each other, or coalesced. ${ }^{[60]}$ In this case, there is no chance for the crack propagation through a continuous liquid film as such a film does not exist. Our recent observations ${ }^{[61]}$ show that a hot tear apparently propagates through the liquid film in more alloyed materials and through solid bridges in less alloyed materials, as illustrated in Figure 4. Although in both cases the fracture surface appears to be brittle, one can suggest that different cracking mechanisms are acting. In real castings, cracks appear above the solidus as well as below the solidus. In the latter case, these cracks are called "cold." There are reports, however, that these cracks, appearing at high temperatures in the fully solid material, can originate in areas of local remelting 
caused by intense local deformation. ${ }^{[62]}$ Thus, formed liquid also assists in crack propagation. These observations make such "cold" cracks in fact similar to hot tears.

Despite a large body of literature on hot tearing, only few efforts have been spent on the mechanism of hot tear propagation. One can mention the application of the Griffith

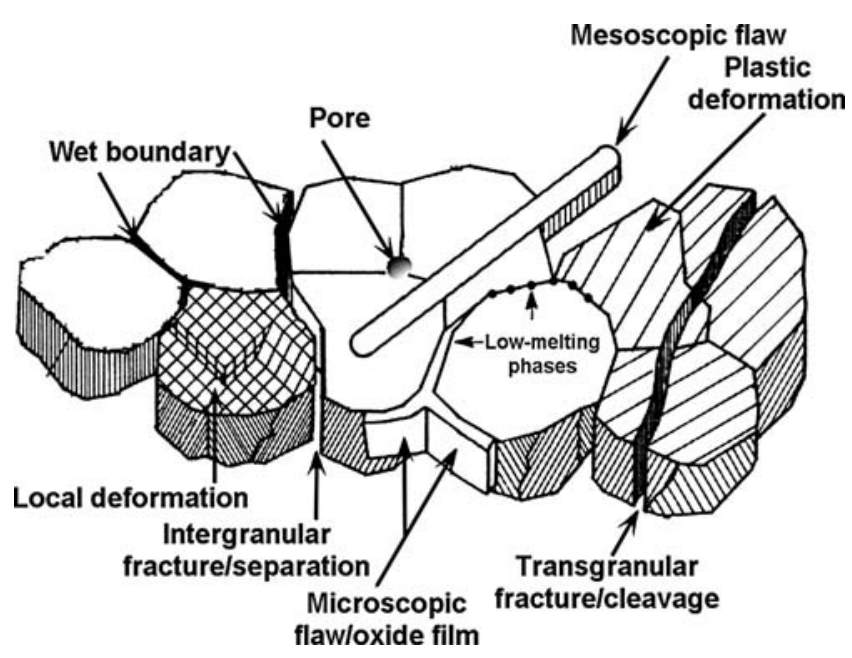

Fig. 3-Schematic illustration of possible hot crack initiators and some crack propagation mechanisms (the initial sketch is adopted from Ref. 63). criterion for brittle fracture ${ }^{[51,57]}$ and vacancy-diffusioncontrolled growth. ${ }^{[23]}$ The methodology for the description of crack propagation is well developed within fracture mechanics for various situations, including those resembling hot cracking, i.e., liquid film rupture, pore coalescence, high-temperature creep, and liquid-assisted fracture. ${ }^{[63]}$ It is clear that the propagation of the hot crack in the potential presence of liquid (above or below the solidus) should involve the following aspects: liquid feeding (involves permeability and, inevitably structure evolution), pore coalescence, stress transfer by solid bridges, plastic deformation and creep of solid bridges in the absence of liquid, and brittle fracture of solid bridges in the presence of liquid. It is also obvious that the hot crack, like any other crack, can develop catastrophically (which is usually assumed), have sustained growth, or stop. Liquid feeding plays a dual role. First, adequate feeding of the shrinking material with liquid does not eliminate the causes of hot tearing but rather "patches" the consequences, which is reflected in the term "crack healing." One can say that a semisolid alloy containing enough liquid at the last stage of solidification, having a microstructure that enables adequate permeability of the mush, and subjected to tensile stresses is a self-healing material. On the other hand, the development of solid bridges between grains at high solid fractions in the absence of any liquid would build up enough strength and ductility to prevent any brittle rupture. Hence, the liquid feeding should be just enough to supply some liquid

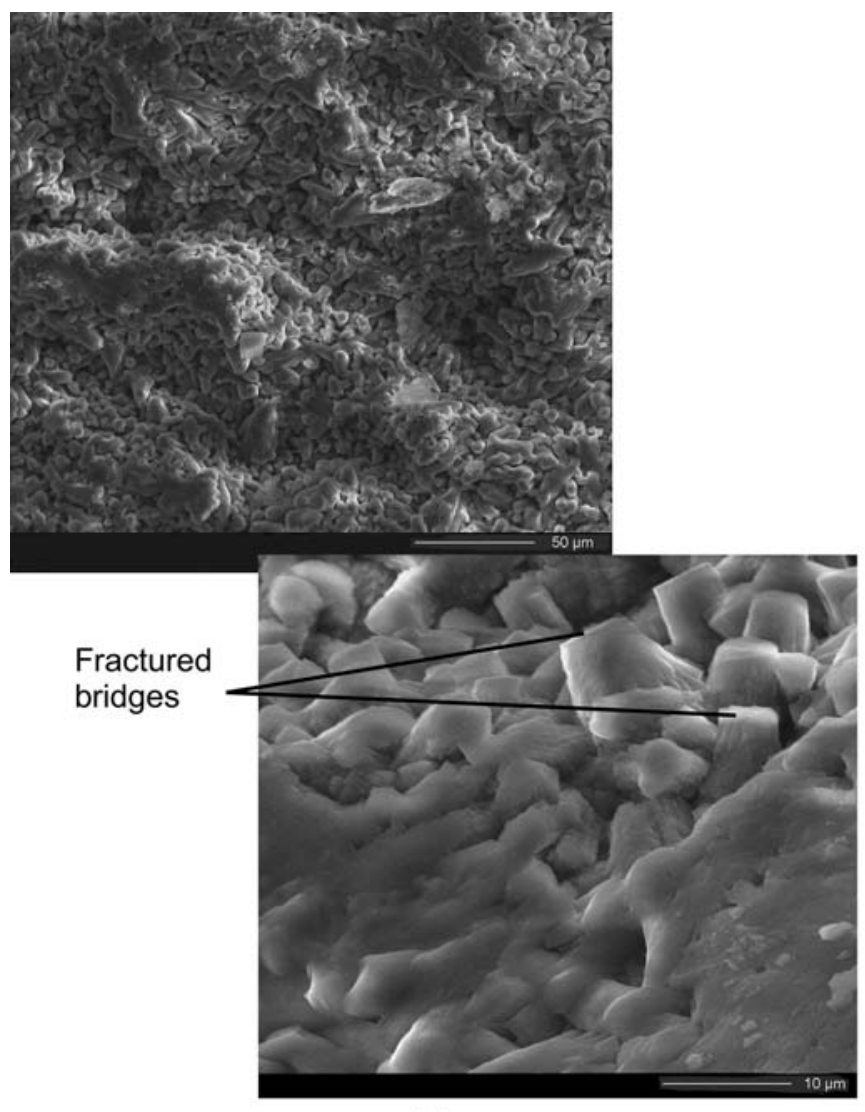

(a)

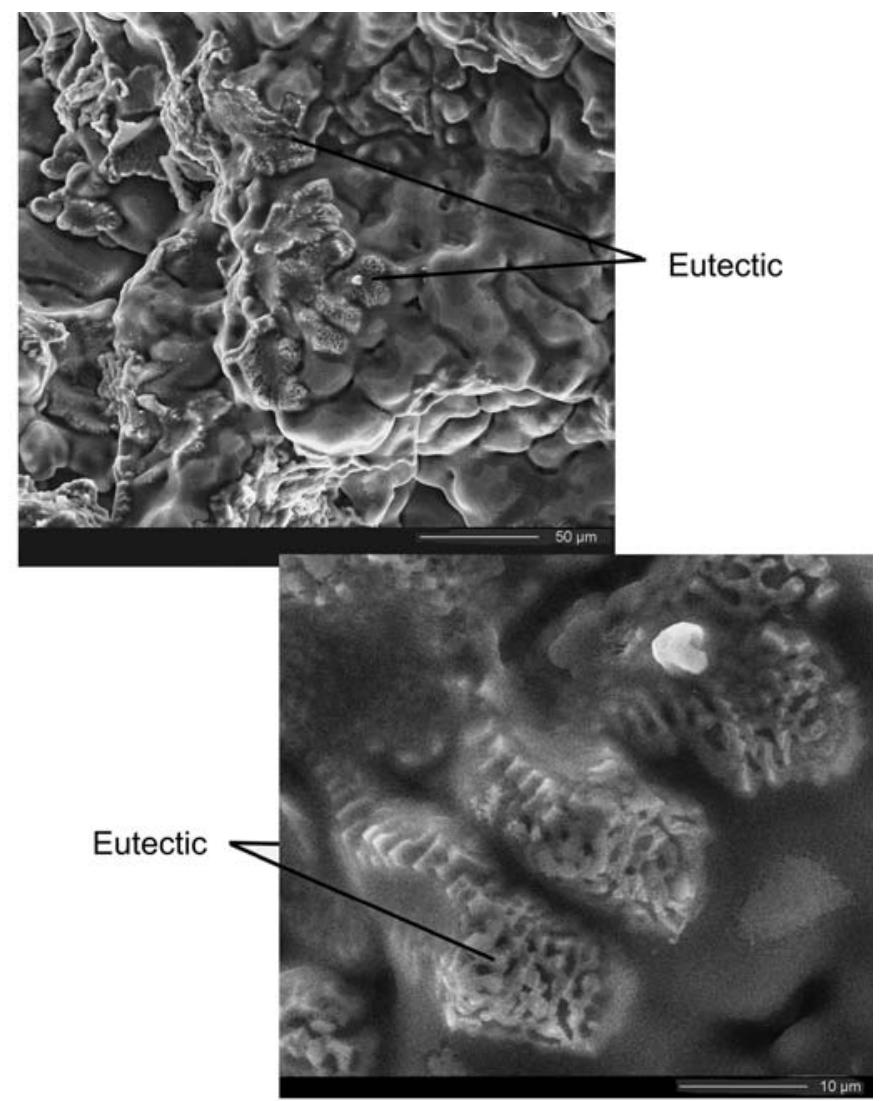

(b)

Fig. 4-Fracture surfaces of hot tears in 200-mm round billet produced by DC casting at a casting speed of $200 \mathrm{~mm} / \mathrm{min}:(a) \mathrm{Al}-1 \mathrm{pct} \mathrm{Cu}$ and $(b) \mathrm{Al}-3 \mathrm{pct} \mathrm{Cu}$. 
to solid bridges that enables their liquid embrittlement; otherwise, only the mechanisms of ductile fracture, e.g., high-temperature creep and pore coalescence, will be active. ${ }^{[8]}$ The evidence of plastic deformation during hot tearing has been observed in direct observations ${ }^{[64]}$ and upon examination of fracture surfaces. ${ }^{[9]}$

We can suggest the following approach to treating the nucleation and propagation of hot cracks. Several distinct mechanisms are operational in different temperature or compositional ranges or, in other words, at different fractions of solid. Here, we will consider only the decreasing temperature as the factor affecting the solid fraction, though the composition is obviously the other factor that acts in a similar manner. It is important to note that the microstructure, e.g., grain size and morphology, affects the critical temperatures and fractions of solid. In most cases, the local stress-strain situation is crucial. Therefore, the stress concentration in specific locations produces the conditions for crack nucleation. The crack initiator in all cases considered below could be represented by pore, liquid pool or film, interface with an intermetallic particle, or nonmetallic inclusion. At relatively low fractions of solid below the coherency temperature, the permeability of the mushy zone enables adequate feeding of the solidification shrinkage and most of the precipitating gas bubbles can float to the liquid part of the sample. In this case, the tensile stresses caused by nonuniform thermal contraction of the coherent dendrites may cause the formation of cavities and gaps that are immediately filled with liquid, or "healed." On further decreasing temperature, the tensile stress builds up to such an extent that the liquid film separating grains ruptures and the formed gap cannot be filled with liquid due to the increasing capillary pressures required to fill ever narrowing openings between grains. On further cooling, the bridging between solid grains replaces former entanglement and touching of grains, and the stress can now be transmitted over larger distances through the rigid solid skeleton; hence, the semisolid body acquires macroscopic strength. This critical temperature is called the "rigidity temperature" and can be determined experimentally. ${ }^{[9,65]}$ Note that the rigidity temperature strongly depends on the structure. ${ }^{[65]}$ The decreased permeability of the mush in combination with solidification shrinkage leads to the local pressure drop that, in combination with the evolving gas, promotes the formation of voids at available interfaces, mainly on grain boundaries and interfaces with inclusions. The nonuniform thermal stress causes rather significant strains in the semisolid material that can be or cannot be sustained by the solid bridges. Even limited access of the liquid to the solid bridge will result in its brittle fracture by the mechanism of liquid-metal embrittlement. This is partially reflected in the proposal of van Haaften et al. ${ }^{[66]}$ to use the fraction of grain boundaries covered with liquid rather than the fraction of liquid in the constitutive equation for the mechanical behavior or semisolid aluminum alloys. The same mechanism may act at subsolidus temperatures when some amount of nonequilibrium liquid is present at grain boundaries or other stress concentrators because of nonequilibrium character of solidification ${ }^{[8]}$ or local remelting. ${ }^{[62]}$ There is also a possibility that the semisolid material fails macroscopically in a brittle manner (because of film rupture and liquid-metal embrittlement) with ductile rupture of some solid bridges on the microscopic level. ${ }^{[64]}$ And, finally, the fraction of bridged grain boundaries becomes so overwhelmingly large and the remaining liquid is so scattered in the solid network that the semisolid material behaves as completely solid and fails in a ductile manner by ductile pore coalescence and high-temperature creep. The outline of these mechanisms is given in Table III. Figures 2 and 3 illustrate the correlation between these mechanisms and the development of the structure during solidification.

A criterion that can predict not the probability but the actual occurrence and extent of hot tearing should be based on the application of multiphase mechanics and fracture mechanics to the failure of semisolid materials, which is today limited by the lack of knowledge about the actual nucleation and propagation mechanisms. The mechanisms outlined in Table III are based on the common sense and interpretation of very few experimental observations. What is needed is a thorough and systematic study of fractures occurring in solidifying materials with the aim to single out the nature and the critical dimensions of defects or structure features that can cause the nucleation of hot cracks. It is also necessary, in our opinion, to acknowledge that different mechanisms of crack propagation are possible at different fractions of solid. Therefore, different models should be

Table III. Possible Mechanisms Acting within "Hot Tearing” Phenomenon

Temperature Range/Fraction

of Solid

Nucleation of Crack*

Propagation of Crack

Fracture Mode

Between coherency and rigidity Grain boundary covered with temperatures; 50 to 80 pct solid

Below rigidity temperature; 80 to 99 pet solid liquid; shrinkage or gas pore Pore, surface of particle or inclusion, liquid film or pool, vacancy clusters

Close to the solidus; 98 to 100 pet solid
Pore, surface of particle or inclusion, segregates at grain boundary, liquid at stress concentration point, vacancy clusters (a) Liquid film rupture

(b) filled gap

(a) Liquid film rupture; liquid metal embrittlement of solid bridges

(b) plastic deformation of bridges

(a) Liquid metal embrittlement

(b) plastic deformation of bridges, creep (a) Brittle, intergranular

(b) healed crack

(a) Brittle, interganular

(b) ductile failure of bridges possible

(a) Brittle, intergranular, transgranular propagation is possible

(b) macroscopically brittle or ductile, intergranular; transgranular propagation is possible

*The crack initiator should be located in the place of stress concentration. 


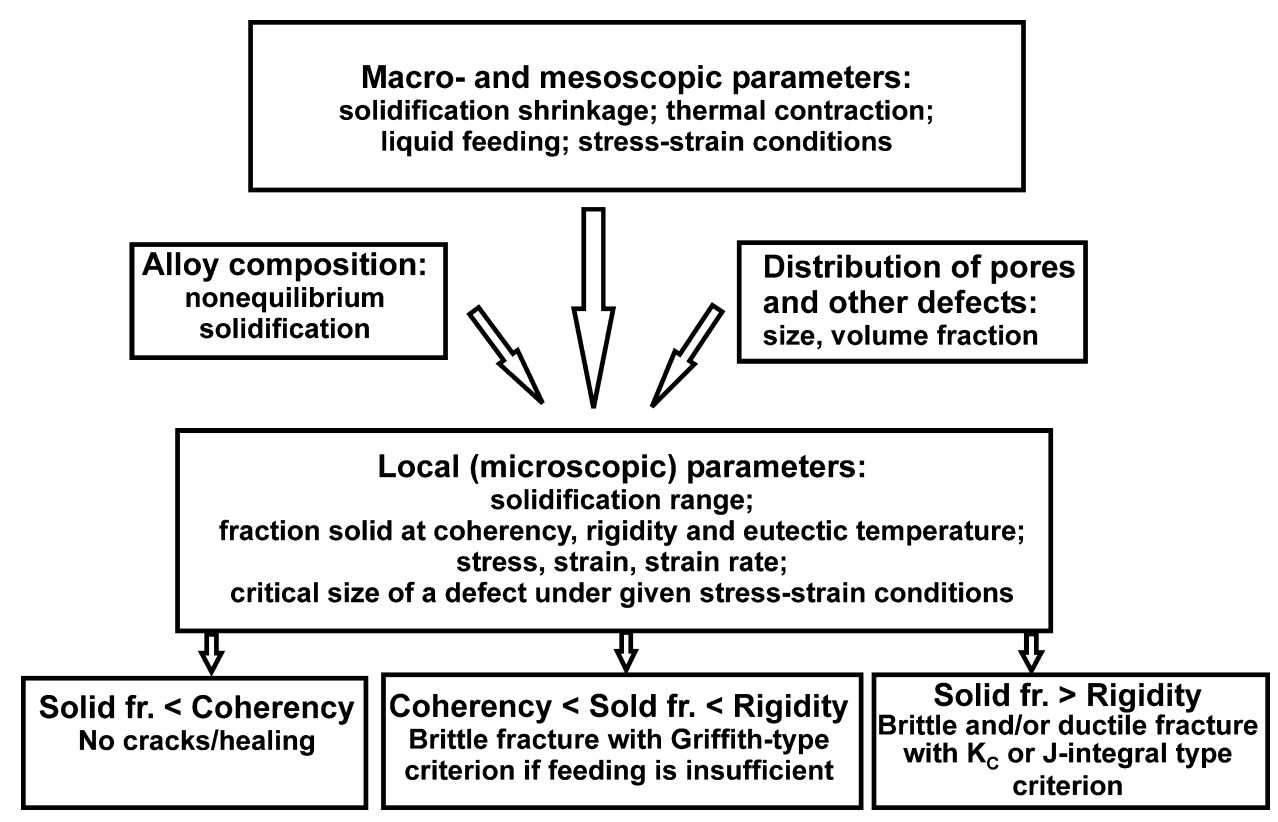

Fig. 5-Flowchart for a new hot tearing criterion.

applied to the development of hot tears in ingots, billets, and castings in dependence on the alloy composition, structure, and level of stresses that are present. For example, coarsegrained material with a large solidification range and high coherency temperature is likely to fail due to liquid film rupture. In the case of alloys with a considerable amount of eutectics, e.g., foundry alloys of the Al-Si system, the healing of cracks is most probable. In contrast, a fine-grained alloy that develops coherency late in solidification and does not contain much of eutectics, e.g., a commercial wrought alloy, will undergo complex failure involving liquid-metal embrittlement and plastic deformation of solid bridges with a resultant mixed brittle/ductile fracture. Figure 5 gives a flowchart for the development of a new hot tearing criterion.

\section{CONCLUDING REMARKS}

The existing hot tearing criteria based on different principles have limited applicability to commercial casting processes, e.g., to direct-chill casting, due to their probabilistic character. The best of the available criteria can successfully predict the probability of hot tearing in its dependence on some casting parameters but fails to forecast the actual occurrence of hot cracks in ingots and billets. There are two main challenges in this endeavor. First, we lack the knowledge of the actual causes of crack nucleation. That is to say, we do not know exactly what defects or structure defects can act as crack initiators under particular temperature-stress conditions. Second, there is a possibility that different mechanisms of crack propagation and final failure act in dependence on the fraction of solid at which the fracture occurs and on the alloy structure. The application of multiphase mechanics and, eventually, fracture mechanics to the phenomenon of hot cracking looks quite promising. The quest for a new hot tearing model and a corresponding hot tearing criterion should focus on these two research areas.

\section{ACKNOWLEDGMENTS}

This article is written within the framework of the research program of the Netherlands Institute for Metals Research (www.nimr.nl), Project Nos. MP4.97014 and MC4.02134. Fruitful remarks from the members of the 7UP Club are greatly acknowledged.

\section{REFERENCES}

1. H.F. Bishop, C.G. Ackerlind, and W.S. Pellini: Trans. Am. Foundrymen's Soc., 1952, vol. 60, pp. 818-33.

2. W.S. Pellini: Foundry, 1952, vol. 80, pp. 124-33 and 192-99.

3. J.C. Borland: Br. Welding J., 1960, vol. 7, pp. 508-12.

4. S.A. Metz and M.C. Flemings: Trans. Am. Foundrymen's Soc., 1970, vol. 78, pp. 453-60.

5. U. Feurer: Giessereiforschung, 1976, vol. 28 (2), pp. 75-80.

6. T.W. Clyne and G.J. Davies: Solidification and Casting of Metals, Metals Society, London, 1979, pp. 275-78.

7. B. Rogberg: Scand. J. Met., 1983, vol. 12, pp. 51-66.

8. J. Campbell: Castings, Butterworth-Heinemann, Oxford, United Kingdom, 1st ed., 1991; and 2nd ed., 2003.

9. I.I. Novikov: Goryachelomkost Tsvetnykh Metallov i Splavov (Hot Shortness of Non-Ferrous Metals and Alloys), Nauka, Moscow, 1966.

10. G.K. Sigworth: Trans. Am. Foundrymen's Soc., 1996, vol. 104, pp. 1053-62.

11. J.A. Spittle and A.A. Cushway: Met. Technol, 1983, vol. 10, pp. 6-13.

12. L. Ohm and S. Engler: Giessereiforschung, 1990, vol. 42 (4), pp. 149-62.

13. M.L. Nedreberg: Ph.D. Thesis, University of Oslo, Oslo, Norway, 1991.

14. J.A. Spittle, S.G.R. Brown, J.D. James, and R.W. Evans: Proc 7th Int. Symp. on Physical Simulation of Casting, Hot Rolling and Welding, National Research Institute for Metals, Tsukuba, Japan, 1997, pp. 81-91.

15. W.-M. van Haaften, W.H. Kool, and L. Katgerman: in Continuous Casting, K. Ehrke and W. Schneider, eds., Wiley-VCH, Weinheim, Germany, 2000, pp. 239-44.

16. I. Farup, J.-M. Drezet, and M. Rappaz: Acta Mater., 2001, vol. 49, pp. 1261-69.

17. D.G. Eskin, Suyitno, and L. Katgerman: Progr. Mater. Sci., 2004, vol. 49, pp. 629-711.

18. B.J. Jang, M. Shkuka, R.W. Smith, M. Sahoo, and M. Sadayappan: Light Metals (Metaux Legers) 2002, Int. Symp. on Light Metals, 
Montreal, Aug. 11-14, 2002, Canadian Institute of Mining, Metallurgy and Petrolium, Montreal, 2002, pp. 71-81.

19. J.F. Grandfield, J.A. Taylor, and C.J. Davidson: Magnesium Technology 2002, 2002 TMS Annual Meeting, Seattle, WA, Feb. 17-21, 2002, TMS, Warrendale, PA, 2002, pp. 207-13.

20. R.W. Heine and P.C. Rosenthal: Principles of Metal Casting, McGrawHill, New York, NY, 1955.

21. V.I. Dobatkin: Nepreryvnoe Lit'e i Liteinye Svoistva Splavov (DirectChill Casting and Casting Properties of Alloys), Oborongiz, Moscow, 1948.

22. J. Verö: Met. Industry, 1936, vol. 48, pp. 431-94.

23. H. Fredriksson, M. Haddad-Sabzevar, K. Hansson, and J. Kron: Mater. Sci. Technol., 2005, vol. 21, pp. 521-29.

24. W. Patterson, S. Engler, and R. Kupfer: Giessereiforschung, 1967, vol. 19 (3), pp. 151-60.

25. M. Braccini, C.L. Martin, M. Suéry, and Y. Bréchet: in Modelling of Casting, Welding and Advanced Solidification Processes IX, P.R. Sahm, P.N. Hansen, and J.G. Conley, eds., Shaker Verlag, Aachen, Germany, 2000, pp. 18-24.

26. J.A. Williams and A.R.E. Singer: Austr. Inst. Met, 1966, vol. 11, pp. 2-9.

27. I.I. Novikov and F.S. Novik: Dokl. Akad. Nauk SSSR. Ser. Fiz., 1963, vol. 7, pp. 1153-55.

28. V.N. Saveiko: Russ. Castings Production, 1961, No. 11, pp. 453-56.

29. C.H. Dickhaus, L. Ohm, and S. Engler: Trans. Am. Foundrymen's Soc., 1994, vol. 101, pp. 677-84.

30. Y.F. Guven and J.D. Hunt: Cast Met., 1988, vol. 1, pp. 104-11.

31. B. Magnin, L. Maenner, L. Katgerman, and S. Engler: Mater. Sci. Forum, 1996, vols. 217-222, pp. 1209-14.

32. D.C.J. Lees: J. Inst. Met, 1946, vol. 72, pp. 343-64.

33. J. Langlais and J.E. Gruzleski: Mater. Sci. Forum, 2000, vols. 331-37, pp. 167-72.

34. D.J. Lahaie and M. Bouchard: Metall. Mater. Trans. B, 2001, vol. 32B, pp. 697-705.

35. A.A. Bochvar: Izv. Akad. Nauk SSSR, Otdel. Tekhn. Nauk, 1942, No. 9, p. 31.

36. W.I. Pumphrey and J.V. Lyons: J. Inst. Met., 1948, vol. 74, pp. 439-55.

37. T.W. Clyne and G.J. Davies: Br. Foundrymen, 1975, vol. 68, pp. 238-44.

38. L. Katgerman: J. Met., 1982, vol. 34 (2), pp. 46-49.

39. D.M. Stefanescu: Int. J. Cast Met. Res., 2005, vol. 18 (3), pp. 129-43.

40. N.N. Prokhorov: Russ. Castings Production, 1962, No. 2, pp. 172-75.

41. M. Rappaz, J.-M. Drezet, and M. Gremaud: Metall. Mater. Trans. A, 1999, vol. 30A, pp. 449-55.

42. E. Niyama: in Japan-US Joint Seminar on Solidification of Metals and Alloys, Japan Society for Promotion of Science, Tokyo, 1977. pp. 271-82.

43. U. Feurer: in Quality Control of Engineering Alloys and the Role of Metals Science, H. Nieswaag and J.W. Schut, eds., Delft University of Technology, Delft, The Netherlands, 1977, pp. 131-45.
44. I. Farup and A. Mo: Metall. Mater. Trans. A, 2000, vol. 31A, pp. 146172.

45. M. M'Hamdi and A. Mo: in Light Metals 2002, W. Schneider, ed., TMS, Warrendale, PA, 2002, pp. 709-16.

46. M. Rappaz, P.-D. Grasso, V. Mathier, J.-M. Drezet, and A. Jacot: in Solidification of Aluminum Alloys, M.G. Chu, D.A. Granger, and Q. Han, eds., TMS, Warrendale, PA, 2005, pp. 179-90.

47. K. Patterson: Giesserei, 1953, vol. 40 (12), pp. 597-605.

48. J.A. Williams and A.R.E. Singer: J. Inst. Met., 1968, vol. 96, pp. 5-12.

49. J.J. Gilman: Proc. 2nd Symp. on Naval Structural Mechanics, E.H. Lee and P.S. Symonds, eds., Pergamon, Oxford, 1960, pp. 43-99.

50. E. Orowan: in Fatigue and Fracture of Metals, W.M. Murray, ed., John Wiley and Sons, New York, 1952, pp. 139-67.

51. Suyitno, W.H. Kool, and L. Katgerman: Mater. Sci. Forum, 2002, vols. 396-402, pp. 179-84.

52. Suyitno, W.H. Kool, and L. Katgerman: Metall. Mater. Trans. A, 2005, vol. 36A, pp. 1537-46.

53. L. Zhao, Baoyin, N. Wang, V. Sahajwalla, and R.D. Pehlke: Int. J. Cast Met. Res., 2000, vol. 13 (3), pp. 167-74.

54. J.F. Grandfield, D.J. Cameron, and J.A. Taylor: in Light Metals 2001, J.L. Anjier, ed., TMS, Warrendale, PA, 2001, pp. 895-901.

55. J.-M. Drezet and M. Rappaz: in Light Metals 2001, J.L. Anjier, ed., TMS, Warrendale, PA, 2001, pp. 887-93.

56. H.B. Dong, M.R.M. Shin, E.C. Kurum, H. Cama, and J.D. Hunt: Metall. Mater. Trans. A, 2003, vol. 34A, pp. 441-47.

57. Suyitno: Ph.D. Thesis, Delft University of Technology, Delft, The Netherlands, 2005.

58. C. Davidson, D. Viano, L. Lu, and D. StJohn: Int. J. Cast Met. Res., 2006, vol. 19 (1), pp. 59-65.

59. Suyitno, D.G. Eskin, V.I. Savran, and L. Katgerman: Metall. Mater. Trans. A, 2004, vol. 35A, pp. 3551-61.

60. Y. Ju: Ph.D. Thesis, Norwegian University of Science and Technology, Trondheim, Norway, 2004.

61. D. Eskin, Suyitno, and L. Katgerman: in Aluminium Cast House Technology 2005, Proc. 9th Australasian Conf., J. Taylor, I. Bainbridge, and J. Granfield, eds., CSIRO Publishing, Collingwood, 2005, pp. 7784.

62. A. Deschamps, S. Péron, Y. Bréchet, J.-C. Ehrström, and L. Poizat: Mater. Sci. Technol., 2002, vol. 18, pp. 1085-91.

63. M. Janssen, J. Zuidema, and R.J.H. Wanhill: Fracture Mechanics, Delft University Press Blue Print, Delft, The Netherlands, 2002.

64. W.-M. van Haaften, W.H. Kool, and L. Katgerman: J. Mater. Eng. Performance, 2002, vol. 11, pp. 537-43.

65. D.G. Eskin, Suyitno, J.F. Mooney, and L. Katgerman: Metall. Mater. Trans. A, 2004, vol. 35A, pp. 1325-35.

66. W.-M. van Haaften, W.H. Kool, and L. Katgerman: Mater. Sci. Eng., A, 2002, vol. 336, pp. 1-6. 